\title{
КИТАЙ: РОБОТИЗАЦИЯ И РАЗВИТИЕ ЭКОНОМИКИ
}

\author{
(c) 2019 Гусарова Светлана Анатольевна \\ доктор экономических наук, доцент, ведущий научный сотрудник \\ Российский экономический университет имени Г.В. Плеханова, Россия, Москва \\ E-mail: s-gusarova@mail.ru \\ (c) 2019 Гусаров Игорь Владимирович \\ директор ООО «Держава-Сервис», Россия, Москва \\ E-mail: igor-gb@mail.ru
}

Авторы провели исследование развития роботизации в Китае. Определили преимущества и проблемы этого процесса. Сделан вывод, что на рост экономики Китая влияет увеличение объема операционного запаса промышленных роботов в стране. Дальнейшее развитие роботизации в Китае будет способствовать увеличению экономического потенциала страны, повышению качества продукции, росту экспорта инновационных высокотехнологичных товаров.

Ключевые слова: Китай, робототехника, развитие экономики, преимущества и недостатки роботизации.

\section{1. Введение}

Роботизация является наивысшей инновационной формой автоматизации производства в разных сферах, при которой роботы (современные инновационные автоматы, некоторые из которых создаются с использованием искусственного интеллекта) полностью или частично заменяют деятельность человека при выполнении наиболее сложных или трудоемких операций в сфере производства и в сервисной сфере. Их внедрение позволяет компаниям оптимизировать свои производственные процессы, повысить эффективность производства, стать более профессиональными, выпускать конкурентоспособную продукцию. Развитием роботизации занимаются многие государства мира, в том числе Китай.

В 2015 году Китай выступил с инициативой «Сделано в Китае» (Made in China 2025 MIC2025), направленной на модернизацию промышленного потенциала страны [5]. Стратегия «Сделано в Китае 2025» направлена на то, чтобы Китай мог закрепить за собой положение мирового лидера в высокотехнологичных сферах, в том числе в робототехнике, в создании искусственного интеллекта, в автоматизации производства. Основанная на развитии китайских исследований и разработок, стратегия рассматривается в качестве важного элемента устойчивого роста и конкурентоспособности Китая на ближайшее десятилетие.

В 2016 году Китай приступил к Плану раз- вития робототехнической отрасли до 2020 года (Development Plan of Robot Industry (2016-2020), в соответствии с которым широкое привлечение иностранных инвестиций позволит увеличить производство промышленных роботов по китайским технологиям до 100 тысяч к 2020 году [3].

Широкое внедрение роботизации направлено на рост производительности труда, на развитие экономик стран. Многие исследователи публикуют научные работы, посвященные экономике Китая. Но вопросы, связанные с развитием роботизации Китая, еще недостаточно изучены. Поэтому выбранная тема исследования является важной и актуальной.

Целью исследования является выявление преимуществ и проблем роботизации в Китае, определение влияния роботизации на рост экономики страны.

2. Развитие робототехники в Китае

В 2018 году объем продаж промышленных роботов в мире увеличился до 422 тыс. единиц (на 6\% больше, чем в 2017 году и в 2,4 раза больше против 2013 года), или до 16,5 млрд. долл. Число операционных запасов роботов в мире превысило 2,4 млн. единиц [8].

Наибольшим глобальным рынком промышленных роботов является Азия. В первую очередь здесь можно выделить Китай, который остается крупнейшим в мире рынком промышленных роботов с долей в 36\% от общего числа их установок. В Китае в 2018 году было продано 
около 154 тысяч роботов [9], что больше в 1,6 раза, чем общее число роботов, проданных в странах Европы и Америки вместе взятых (входящих в ТОП-15 крупнейших рынков промышленных роботов в мире). Объем продаж в стоимостном выражении составил 5,4 млрд. долл. (в 1,2 раза больше уровня 2017 года). В КНР продается каждый третий промышленный робот в глобальной экономике.

Около трети роботов, продаваемых на внутреннем рынке Китая в 2018 году (27\%), было создано китайскими специалистами, что соответствует политике Китая, направленной на продвижение отечественных создателей и производителей инновационной продукции.

Несмотря на то, что по интенсивности проникновения робототехники в производственные операции Китай находится лишь на двадцатом месте в мире, этот показатель за 2010-2018 годы увеличился в 88,3 раза и в 2018 году составил 140 роботов [4], что в 1,4 раза больше среднемирового уровня.

Основными отраслями, в которых внедряются роботы в Китае, являются: электроника, автомобилестроение и металлургия. За 2016-2018 годы количество роботов, внедренных в электронику, увеличилось в 1,5 раза (до 50 тысяч роботов), в автомобилестроение - в 1,4 раза (43 тысячи роботов), в металлургию и металлообработку - в 1,7 раз (20 тысяч роботов) [4], в производство резины и пластика - в 1,3 раза, в производства продовольствия - в 2 раза.

В Китае в области робототехники работают более 800 высокотехнологичных компаний. Ими было произведено в 2016 году 72,4 тысячи роботов [2]. Китайские компании внедряют в свое производство технологию больших данных (Big Data), интернета вещей (Internet of Things), облачных вычислений (cloud computing). Китай стремится как приобретать высокотехнологичные компании из разных государств мира, так и развивать создание и производство робототехники внутри страны.

Участвуя в приобретении крупных высокотехнологичных мировых компаний в альянсе с другими передовыми компаниями, занимающимися созданием робототехники, Китай ускоряет роботизацию страны, получая инновационные технологии. Китайская компания (Midea Group Co) приобрела за 5 млрд. долл., одну из крупнейших в мире компаний в области робототехники, немецкую компанию, входящую в большую четверку ведущих мировых производителей промышленных роботов (Kuka AG). Кроме того, китайская компания (Midea Group Со) занимается строительством «умных фабрик» в некоторых китайских городах, инвестировав 725 млн. долл. в создание 1500 роботов.

Китайская компания (Galanz), являющаяся одним из крупнейших в мире производителей микроволновых печей, заключила договор о стратегическом партнерстве с японской компанией, входящей в большую четверку ведущих мировых производителей промышленных роботов (Fanuc), что позволило компании получить инновационные технологии.

Совместное предприятие между китайской компанией (Zhongke Ruiguang) - производителем высокоскоростных компьютеров и американским разработчиком искусственного интеллекта (компанией VMware), позволило внедрить на китайском рынке новую облачную операционную систему (Cloudview SVM Edition V3).

В Южном Китае более 1500 предприятий внедряют роботов. Например, компания, занимающаяся производством модулей мобильных телефонов в Дунгуане (Changying Precision Technology Company) заменила 90\% сотрудников (или 590 человек) на роботов. Внедрение роботов позволило повысить производительность труда в 2,5 раза [7].

Китай проявляет большую заинтересованность в создании собственных производств роботов. Например, китайская робототехническая компания (E-Deodor - дочерняя компания Ningbo Techmation) производит оборудование для пластиковой промышленности цена которого в 1,2 раза меньше, чем аналогичное иностранное оборудование (производимое компаниями АBB, Kawasaki).

Китайская компания (Unitree Robotics) со3дала робот (AlienGo), оснащенный стереокамерой, способный передвигать предметы, превосходящие его вес во много раз, являющийся конкурентом робота (SpotMini), разработанного известной фирмой (Boston Dynamics),

Компания «Китайская информационно-коммуникационная технология» (China Information Communication Technology) открыла совместно с компанией (China Mobile) в городе Ухань первую в Китае уникальную производственную линию и промышленную интернет-лабораторию (на базе технологии $5 \mathrm{G}$ ), что позволило увеличить производительность промышленных роботизирован- 
ных манипуляторов в 1,3 раза [1].

В перспективе Китай заинтересован в создании такого производства, где роботов будут производить роботы. Одним из крупнейших в мире производителем робототехники является швейцарская компания $\mathrm{ABB}$, инвестировавшая 150 млн. долл. в строительство в Шанхае инновационного высокотехнологичного робототехнического завода, на котором в 2020 году роботы будут производить до 100 тысяч роботов в год [6]. Для создания «фабрики будущего» будут объединены исследования связанных цифровых технологий, совместной робототехники и искусственного интеллекта, разработанные швейцарской компанией АBB. Компания АBB создала программное обеспечение (SafeMove2), которое позволяет сотрудникам завода и роботам, созданным компанией (YuMi) при решении наиболее сложных сборочных задач безопасно осуществлять совместную деятельность.

Преимуществом Китая по внедрению инновационных технологий создания роботов является обширный внутренний рынок. Развитие роботизации Китая приведет в будущем к повышению эффективности производства, к росту экспорта инновационных высокотехнологичных товаров, к развитию экономики страны.

\section{3. Влияние роботизации Китая на рост} ВВП

Операционный запас промышленных роботов в Китае увеличился за 2008-2018 годы в 20,3 раза до 649 тысяч роботов [3]. Для определения влияния развития робототехники в Китае на рост ВВП был проведен корреляционный и регрессионный анализы. На основе корреляционного анализа выявлена тесная взаимосвязь объема операционного запаса промышленных роботов в Китае с объемом его ВВП за 2008-2018 годы (коэффициент корреляции был 0,8909).

При решении уравнения регрессии (формула 1) применялся метод наименьших квадратов и матричный метод.

$$
Y=\beta_{1} X_{1}+\beta_{0}
$$

где $\beta_{0}-$ свободный член, определяющий значение ВВП (Y) в случае, если факторный признак $\left(X_{1}\right)$ равен нулю;

$\beta_{1}-$ коэффициент регрессии первого факторного признака $\left(X_{1}\right)$.

$$
\beta_{1}=S P / S S x
$$

где $S P$ - сумма перекрестных произведений между двумя производными $\left(X_{1}\right.$ и $\left.Y\right)$;

$S S x$ - сумма квадратов отклонений от среднего значения $X_{1}$.

$$
S P=\sum\left(X_{1}-M X_{1}\right)(Y-M Y)
$$

где $M X_{1}-$ среднеарифметическое значение $X_{1}$;

$M Y$ - среднеарифметическое значение $Y$.

$$
S S x=\sum\left(X_{1}-M X_{1}\right)^{2}
$$

В результате регрессионного анализа было получено следующее уравнение регрессии: $Y=128168.34 \mathrm{x}_{1}+6310.81$.

На основе регрессионного анализа сделан следующий вывод: увеличение объема операционного запаса промышленных роботов в Китае на 1 единицу приводит в среднем к повышению объема ВВП Китая на 128168,3 долл.

\section{4. Выводы}

Проведенное исследование роботизации в Китае позволило определить достоинства и недостатки этого процесса. Основными преимуществами роботизации в Китае являются: повышение производительности труда; рост объема ВВП страны, увеличение экономического потенциала; оптимизация структуры экономики; модернизация и автоматизация производства; внедрение современных технологий и современных форм и методов управления; повышение качества продукции и конкурентоспособности экспорта; развитие научных исследований и разработок; сокращение объемов тяжелого непроизводительного труда; внедрение роботов на вредных участках производства; повышение квалификации рабочей силы, создание новых высококвалифицированных рабочих мест.

Основными проблемами роботизации в Китае являются: рост неравенства в доходах граждан Китая; потеря населением рабочих мест и заработной платы; снижение объема внутреннего потребления; рост нехватки высококвалифицированного трудоспособного населения; обострение зависимости роста экономики Китая от экспорта.

Решение этих вопросов позволит повысить производительность труда, уровень развития экономики страны, благосостояние народа. 


\section{Библиографический список}

1. China Mobile, CICT Open Country’s First Smart 5G production Line [Электронный pecypc] // Yicai Global.- Peжим доступа: https://yicaiglobal.com/news/china-mobile-cict-open-country-first-smart-5g-production-line (дата обращения: 10.04.2019).

2. China's Robot Revolution May Affect the Global Economy [Электронный ресурс] // Bloomberg.- Режим доступа: https://www.bloomberg.com/news/articles/2017-08-22/china-s-robot-revolution-may-weigh-on-globalrebalancing (дата обращения: 22.08.2017).

3. Development Plan of Robot Industry (2016-2020) [Электронный ресурс] // CNYD.- Режим доступа: httр:// en.cnydsci.com/html/news/meiti/122.html (дата обращения: 23.05.2017).

4. IFR World Robotics Presentation [Электронный ресурс] // International Federation of Robotics.- Режим доступа: https://ifr.org/downloads/press2018/IFR\%20World\%20Robotics\%20Presentation\%20-\%2018\%20Sept\%20 2019.pdf (дата обращения: 23.08.2019).

5. Made in China 2025 [Электронный ресурс] // The State Council. The People’s Republic Of China.- Режим доступа: http://english.www.gov.cn/2016special/madeinchina2025/ (дата обращения: 25.08.2019).

6. Mogg Trevor. Robot uprising a step closer with plan for factory where they build themselves [Электронный peсурс] // Digital trends. - Режим доступа: https://www.digitaltrends.com/cool-tech/robots-to-make-robots-atone-of-the-worlds-most-advanced-facilities/ (дата обращения: 28.10.2018).

7. Prakash Abishur. Forget The Markets, Robots Are China’s New Worry [Электронный ресурс] // Forbes.- Peжим доступа: https://www.forbes.com/sites/realspin/2016/01/28/forget-the-markets-robots-are-chinas-newworry/\#211bce083cb7 (дата обращения: 28.01.2016).

8. Press Release IFR World Robotics 2019 [Электронный ресурс] // International Federation of Robotics. - Peжим доступа: https://ifr.org/downloads/press2018/2019-09-18_Press_Release_IFR_World_Robotics_2019_Industrial_ Robots_English.pdf (дата обращения: 23.08.2019). 